\title{
Título da página electrónica: Graphic Sociology
}

URL: http://thesocietypages.org/graphicsociology/

\section{Francisco Freitas}

\section{OpenEdition}

\section{Journals}

Edição electrónica

URL: http://journals.openedition.org/rccs/1618

DOI: $10.4000 /$ rccs. 1618

ISSN: 2182-7435

\section{Editora}

Centro de Estudos Sociais da Universidade de Coimbra

Edição impressa

Data de publição: 1 setembro 2011

Paginação: 130

ISSN: 0254-1106

Refêrencia eletrónica

Francisco Freitas, "Título da página electrónica: Graphic Sociology », Revista Crítica de Ciências Sociais [Online], 94 | 2011, posto online no dia 01 dezembro 2012, consultado o 21 setembro 2020. URL : http://journals.openedition.org/rccs/1618; DOI : https://doi.org/10.4000/rccs.1618 


\section{Espaço Virtual}

\section{Título da página electrónica: EM-DAT, The International Disaster Database URL: http://www.emdat.be/}

A obtenção de dados sobre os impactos produzidos por desastres de índole natural ou tecnológica é importante para a actuação de governos e agências internacionais. Por outro lado, tais dados possibilitam leituras várias sobre a realidade de determinado país, desde logo porque a informação em torno destes acontecimentos é reveladora do estádio de desenvolvimento existente ou do grau de vulnerabilidade de determinada população. A constituição de uma base mundial sobre esta temática é uma tarefa notável que está sujeita a diversas dificuldades, uma vez que as definições de determinados fenómenos variam, as metodologias para a recolha de dados nos diferentes países também são díspares e pelo facto, não menos importante, de ser necessário o recurso a uma gama variada de fontes de informação. Esse é, pois, o propósito da EM-DAT, uma base de dados sobre desastres da responsabilidade do CRED, Centre for Research on the Epidemiology of Disasters, que resulta da compilação de dados estandardizados. Fundado em 1973, o CRED pertence à Universidade Católica de Lovaina e é responsável pela recolha, análise, validação e publicação desses dados. Tem, para esse fim, vários convénios e parcerias estabelecidos, quer com as principais universidades mundiais, quer com organizações internacionais que atuam no âmbito da ajuda humanitária. Além do portal DISDAT, dedicado à recolha de dados sobre este tipo de eventos, o utilizador pode consultar um vasto conjunto de publicações, notas explicativas e um glossário. Na navegação pela base de dados existe um conjunto de serviços predefinidos, dos quais se destacam vários perfis, nomeadamente um perfil para países, de acordo com os desastres ocorridos no mesmo, um perfil para desastres, em que os mesmos são descritos e surgem agrupados por categorias, uma lista de desastres, que permite a pesquisa através da definição de critérios como espaço, tempo ou tipo/grupo de desastre, etc. Este serviço disponibiliza, também, diversas representações cartográficas e gráficas, estas últimas relativas a tendências observadas desde o início do século XX nesta temática, algo muito importante dado que muitos destes fenómenos devem ser analisados através do recurso a séries temporais longas.

A base de dados é de acesso livre, pelo que qualquer utilizador consegue aceder a uma gama de dados diversificada que nem sempre está disponível nos respetivos países de origem. Acresce, ainda, a possibilidade de o utilizador definir a sua própria base de dados através de mecanismos de pesquisa avançada, não sendo requeridos conhecimentos especializados de microinformática para tal. Por fim, é de referir que, assim como noutras esferas, também os dados obtidos através desta base devem ser cruzados com outras fontes, desde logo porque, face aos constrangimentos metodológicos existentes, é expectável que surjam valores desajustados. Ainda assim, é importante constatar que, uma vez considerados e cruzados critérios como o impacto humano, as perdas económicas ou a ajuda internacional disponibilizada, é comum verificarmos que acontecimentos com os resultados mais desastrosos não obtêm uma inclusão adequada na agenda pública. 


\section{Título da página electrónica: Graphic Sociology URL: http://thesocietypages.org/graphicsociology/}

Atualmente as preocupações com a representação de dados provenientes de investigação têm vindo a aumentar. De facto, para lá da efetivação de determinado esquema de investigação ou do respeito pelos preceitos metodológicos necessários, vai emergindo a necessidade de comunicar os resultados a uma gama mais alargada de públicos, de forma a que os trabalhos não fiquem simplesmente confinados à academia. Nesse sentido, se elementos como gráficos, diagramas ou redes de ligações são desde há muito utilizados para representar determinadas relações, porventura existirá hoje uma maior preocupação com os resultados obtidos ou com a facilidade da sua leitura. Face aos artefactos disponíveis e à facilidade cada vez mais maior no acesso à tecnologia, é percetível um crescente enfoque na apresentação visual de informação, seja através de gráficos, seja por via de outro tipo de representações. A esse nível, muitas das ferramentas e/ou tecnologias estão democratizadas, não se confinando necessariamente a determinado grupo de profissionais com formação específica. Por outro lado, também o enfoque na multidisciplinaridade conduz, por vezes, a este tipo de resultados. O blogue Graphic Sociology funciona, pois, como um reportório onde é possível aceder a um vasto conjunto de trabalhos em que existiu uma particular preocupação com a representação dos dados. Tal como é explicitado, assim como no meio académico é exigido que se escreva de forma clara, também a representação de dados deve ser alvo de atenção especial dada a sua natureza interativa, que exige tempo, prática e revisão pelos pares. O objetivo fundamental deste blogue é, pois, um rebalancear do processo de comunicação, fazendo com que na ciência social exista mais preocupação com a integração de informação gráfica que otimize a mensagem final e não comprometa a apresentação de resultados.

Este blogue inclui-se no portal Society Pages, um projeto de ciência social multidisciplinar difundido pelo Departamento de Sociologia da Universidade de Minesota. A missão expressa passa por veicular o conhecimento e informação científicos a um público mais lato, de forma a conferir maior visibilidade e influência às atividades de investigação. Nesse sentido, o blogue apresentado é mais uma das páginas comunitárias disponibilizadas pelo projeto para a prossecução de tal fim.

\section{Francisco Freitas}

